\title{
Barriers and Facilitators to Recruitment to a Culturally Based Dietary Intervention Among Urban Hispanic Breast Cancer Survivors
}

\author{
Blanca Bernard-Davila - A. Corina Aycinena • John Richardson • Ann Ogden Gaffney • \\ Pam Koch • Isobel Contento • Christine Sardo Molmenti • Maria Alvarez • \\ Dawn Hershman • Heather Greenlee
}

Received: 12 July 2014 / Revised: 7 October 2014 / Accepted: 24 November 2014 / Published online: 10 December 2014

(C) W. Montague Cobb-NMA Health Institute 2014

\begin{abstract}
Purpose The purpose of this study was to understand factors related to recruitment to behavioral intervention trials among Spanish-speaking urban Hispanic breast cancer (BC) survivors.

Methods Potentially eligible Hispanic BC survivors were recruited from the Columbia University Breast Oncology Clinic, signed informed consent, and completed a screening interview on demographics, medical history, acculturation (Short Acculturation Scale for Hispanics), quality of life (QOL), and perceived benefits/risks of research participation. Trial eligibility criteria included stage 0 -III BC, completion of adjuvant treatment, Hispanic descent, fluency in Spanish, and willingness to be randomized to active arm (9-session in-person culturally based ¡Cocinar para su salud! dietary modification program) or control arm (written materials). We compared
\end{abstract}

B. Bernard-Davila $\cdot$ A. C. Aycinena $\cdot$ J. Richardson

C. S. Molmenti $\cdot$ D. Hershman $\cdot$ H. Greenlee

Department of Epidemiology, Mailman School of Public Health, Columbia University, 722 West 168th St., 7th Floor, New York, NY 10032, USA

A. C. Aycinena - C. S. Molmenti - M. Alvarez - D. Hershman • H. Greenlee $(\triangle)$

Herbert Irving Comprehensive Cancer Center, Columbia University

Medical Center, New York, NY, USA

e-mail: hg2120@columbia.edu

A. C. Aycinena $\cdot$ P. Koch $\cdot$ I. Contento

Department of Health and Behavior Studies, Teachers College,

Columbia University, New York, NY, USA

D. Hershman

Department of Medicine, College of Physicians and Surgeons, Columbia University, New York, NY, USA

A. O. Gaffney

Cook For Your Life, New York, NY, USA characteristics between eligible women who did and did not enroll in the trial.

Results One hundred two women completed the screening interview and were eligible to participate. Overall mean age was $57.3 \pm 9.5$ years, mean time since diagnosis was $3.4 \pm$ 2.1 years, $71 \%$ reported annual household income

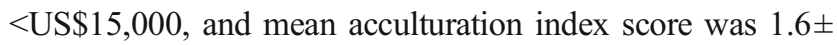
0.6 (scale 1-5, low-high). Of the 102 women, 70 enrolled and 32 declined participation. Reasons stated for non-participation included lack of interest in dietary change, illness, and work constraints. Compared to women who enrolled, women who did not enroll were less likely to be employed $(P=0.03)$ and more likely to only read/speak Spanish $(P=0.02)$. Compared to women who enrolled, non-enrollers were more likely to state that research is costly to participants $(P=0.03)$.

Conclusion Lower participation was associated with unemployment, monolingualism, and the perception that research is costly to participants. Future behavioral intervention trials among minority BC survivors need to account for these and other factors that may be related to trial participation.

Keywords Minority recruitment · Trials · Breast cancer

\section{Introduction}

Substantial cancer disparities exist among Hispanics, compared to other populations. While the incidence of breast cancer is lower among Hispanic women, when compared to non-Hispanic white women, they are more likely to be diagnosed with larger, more advanced tumors, which are ultimately more difficult to cure and lead to poorer outcomes [1]. Modifiable lifestyle behaviors such as body weight, diet, and physical activity before and after diagnosis affect cancer 
outcomes [2-6] and are emerging as important targets for behavioral intervention trials.

In an effort to reliably and successfully study the association between specific lifestyle behaviors and cancer risk and recurrence, targeted intervention trials must adequately recruit and retain a representative group of participants. However, there are several barriers to recruitment especially among underrepresented ethnic and racial groups, such as Hispanic women [7-9]. Strategies are needed to mitigate these barriers so that an ethnically diverse population participates in cancer prevention and control clinical trials.

Hispanics now represent the largest ethnic minority group in the USA (16.7 \% of the total US population) [10]. Over the past three decades, the Hispanic population has grown substantially in urban areas [11]. In 2010, almost half (45\%) of US Hispanics lived in ten major metropolitan areas [12]. Spanish language remains a core characteristic of this population. According to the Pew Research Center's 2013 National Survey of Latinos, $75 \%$ of Hispanics age 5 and older speak Spanish, $74 \%$ speak Spanish at home, and $38 \%$ are Spanish language dominant [13]. Despite the growing size and visibility of the US Hispanic population, Hispanics are less likely to participate in research compared to other racial/ethnic groups [14-16], including clinical trials [17]. There are limited data explaining characteristics associated with non-participation among Hispanics who are otherwise eligible for clinical trials. Historically, studies investigating clinical trial participation among minorities have focused on demographic factors, including historical, social, and economic predictors of consent and participation [18]. Recent studies have begun to examine factors associated with willingness to consent [19-21]. General mistrust in research, socioeconomic constraints, and cultural differences have been identified as key barriers that impact participation rates $[7,9,22-24]$.

In order to improve the recruitment and retention of underrepresented populations in clinical trials, it is important to understand social, cultural, and clinical factors that impede and facilitate clinical trial participation. The goal of this analysis was to identify factors associated with non-enrollment (barriers) and greater enrollment (facilitators) in a behavioral intervention trial targeted to Spanish-speaking Hispanic breast cancer survivors. In this analysis, we compare characteristics of eligible Hispanic women who did and did not choose to enroll in the culturally based dietary modification trial, ¡Cocinar para su salud! (Cook for your life!). The goal of this work was to identify factors related to participation in this trial so that future trials can account for these factors during the study design process and trial implementation.

\section{Methods}

\section{Study Description}

We conducted a descriptive analysis using data collected from urban Spanish-speaking Hispanic breast cancer survivors who were screened for participation in the behavioral intervention trial, ¡Cocinar para su salud!. Participants were recruited from January to August 2012. A total of 102 participants completed the screening questionnaire and were eligible to participate in this study. Of these, 70 participants enrolled in the trial. The primary objective of this predefined analysis was to identify barriers and facilitators to recruitment by examining differences between eligible women who did and did not enroll.

The ¡Cocinar para su salud! trial has been previously described [25-27]. In brief, ¡Cocinar para su salud! examined the effects of a 12-week/9-session in-person dietary intervention versus standard of care written dietary recommendations on change in daily intake of fruit/vegetables and dietary fat at 6 months. Secondary objectives included examining the effects of the intervention at 6 and 12 months on biomarkers of fruit and vegetable intake, molecular biomarkers associated with breast cancer risk, anthropometric measures, fat-related dietary habits, mediators of dietary change, and changes in quality of life and anxiety/depression. All study staff were bilingual in Spanish and English. The dietary intervention used a hands-on educational approach to address determinants of nutritional behavior change including motivational, behavioral, and environmental capabilities. The intervention was culturally based and incorporated the use of native language and culture. Sessions provided culturally adapted recipes and nutrition information. All sessions were conducted in Spanish in order to provide a unified group-based format. The sessions ranged from 1.5 to $3.5 \mathrm{~h}$ and were held on Saturday mornings at the teaching kitchen at Columbia University's Teachers College, located close to bus stops and subway stations. For each session, participants were provided free round trip metrocards to use on New York City's public transportation system.

Potentially eligible participants were recruited from within the Columbia University Medical Center Breast Oncology Clinic. Study recruiters and interviewers were bilingual and Hispanic, reflective of the patient population. Participants signed written informed consent and completed an in-person interviewer-administered screening interview on demographics, medical history, acculturation, quality of life (QOL), and perceived benefits/risks of research participation. Typically, a single staff member conducted both the consent process and the screening interviews on the same day. Occasionally, due to patient time constraints, the screening interview was conducted by phone by a different staff member within 1-2 weeks. Medical record reviews provided data on 
breast cancer pathology and treatment history. Trial eligibility criteria included stage 0 -III breast cancer, at least 3 months post completion of adjuvant treatment, self-defined Hispanic descent (typically South American, Central American, or Caribbean), fluency in Spanish, and willingness to be randomized to active or control arms. Participants were enrolled into the trial in cohorts to allow for class sizes of 4-12 participants, and thus there was a lag between completing the screening interview and starting trial participation. Trial participation began with a baseline clinic visit and interview prior to trial randomization. Eligible women were contacted to schedule their baseline clinic visit, which at the time some women stated that they chose not to participate. Institutional review boards of participating institutions approved the study, and written informed consent was obtained from all participants prior to completing the screening interview.

\section{Measures}

\section{Acculturation Index}

Acculturation was assessed using the Short Acculturation Scale for Hispanics (SASH) [28, 29]. The acculturation index was defined by specific measures including language, social dynamics, and diet. A 5-point Likert scale was used for scoring. The index scale range was defined as low (1) to high (5). The score for each item was summed.

\section{Quality of Life}

Quality of life was assessed with a single question "In general, what would you say your quality of life is?" Response options were on a 5-point Likert scale including poor, fair, good, very good, and excellent.

\section{Comorbidity Index}

A comorbidity index was developed based upon methods reported by Charlson et al. [30] and Patterson et al. [31]. The index incorporated diseases and conditions related to morbidities that predict breast cancer survivor outcomes and categorized various symptomatic manifestations of disease and body systems via general groupings. Twelve general health conditions were assigned weights based on the extent of potential impact on clinical outcomes. Conditions included ulcers, diabetes, neurological problems, gastrointestinal problems, respiration problems, risk factors for heart disease (weight $=1$ point); kidney disease, heart problems, chest pain, physical limitations (weight $=2$ points); and HIV/AIDS and cancer other than breast cancer (weight $=3$ points). The comorbidity index score was computed for each participant by summing the weighted values for each comorbid condition (possible index range $0-20$ points).

\section{Perceptions of Research}

Based upon the investigators' clinical and research experience with this patient population, questions were developed to ascertain participants' perceptions of research, similar to other existing questionnaires in this area [32,33]. Perceptions were assessed by asking how much participants agreed with the following statements: "If you participate in research, you will get better medical care than you would get otherwise," "If you participate in research, you may experience side effects that the doctors cannot predict," "If you participate in research, you can help others," "If you participate in research, your personal information will be kept confidential," "If you participate in research, it will cost you too much time," "The doctors who do research care more about research than about the patients," "If you participate in research, it will take too much time," "If you participate in research, you should be paid for it," and "If you participate in research, you have to fill out a lot of confusing forms." Response options were "strongly agree, disagree strongly, agree somewhat, strongly agree."

\section{Statistical Analysis}

Participant characteristics were compared between two groups: those who were eligible and enrolled into the trial and those who were eligible but chose not to enroll. Associations between participant characteristics and potential factors related to participation were examined using chi-square or Fisher's exact test for categorical variables and $t$ tests or ANOVA for continuous variables. All $P$ values are twotailed and $P$ values $<0.05$ were considered statistically significant. Data analysis was performed using Stata version 12.1.

\section{Results}

\section{Demographic Characteristics}

Of the 111 Spanish-speaking Hispanic breast cancer survivors who provided consent, 102 women completed a screening interview and were eligible to participate in the trial. Of the 102 eligible women, 70 enrolled and 32 did not enroll. Study participant characteristics at the time of screening are presented in Table 1, by enrollment status. The overall sample mean age was 57.3 years (SD 9.5) and the predominant nationality reported was Dominican (77.5\%). Twenty-two percent of the sample completed high school, most were employed full time $(20.6 \%)$, and the majority of participants had a household income that was below the New York City median household income level (>US\$15,000 per year (70.6\%)) [10]. The study sample population reflects the target population of Hispanic breast cancer survivors and is representative of the population 
Table 1 Demographic, lifestyle, and clinical characteristics comparing eligible participants who did and did not enroll in the dietary intervention trial

\begin{tabular}{|c|c|c|c|c|c|}
\hline & \multicolumn{2}{|c|}{ Enrolled $(n=70)$} & \multicolumn{2}{|c|}{ Non-enrolled $(n=32)$} & \multirow[t]{2}{*}{$P$ value } \\
\hline & $n$ & $\%$ & $n$ & $\%$ & \\
\hline \multicolumn{6}{|l|}{ Demographic characteristics } \\
\hline Age mean (SD) & \multicolumn{2}{|l|}{$56.4(9.6)$} & \multicolumn{2}{|c|}{$59.3(8.9)$} & 0.14 \\
\hline Race/ethnicity & & & & & 0.13 \\
\hline Black & 18 & 25.7 & 9 & 28.1 & \\
\hline White & 28 & 40.0 & 11 & 34.4 & \\
\hline Native American & 2 & 2.9 & 4 & 12.5 & \\
\hline Mixed race & 11 & 15.7 & 1 & 3.1 & \\
\hline Nationality & & & & & 0.82 \\
\hline Colombian & 1 & 1.4 & 0 & 0.0 & \\
\hline Cuban & 1 & 1.4 & 0 & 0.0 & \\
\hline Dominican & 54 & 77.1 & 25 & 78.1 & \\
\hline Ecuadorian & 5 & 7.1 & 2 & 6.2 & \\
\hline El Salvadorian & 1 & 1.4 & 0 & 0.0 & \\
\hline Honduran & 1 & 1.4 & 0 & 0.0 & \\
\hline Mexican & 1 & 1.4 & 0 & 0.0 & \\
\hline Puerto Rican & 5 & 7.1 & 5 & 15.6 & \\
\hline Costa Rican & 1 & 1.4 & 0 & 0.0 & \\
\hline Education & & & & & 0.30 \\
\hline Less than high school & 24 & 34.3 & 15 & 46.9 & \\
\hline High school or GED & 18 & 25.7 & 4 & 2.5 & \\
\hline Some college & 20 & 28.6 & 7 & 21.9 & \\
\hline College or higher & 7 & 10.0 & 4 & 12.5 & \\
\hline Employment status & & & & & 0.05 \\
\hline Full time & 18 & 25.7 & 3 & 9.4 & \\
\hline Part time & 10 & 14.3 & 3 & 9.4 & \\
\hline Retired & 6 & 8.6 & 2 & 6.2 & \\
\hline Homemaker & 14 & 20.0 & 3 & 9.4 & \\
\hline Unemployed & 5 & 7.1 & 3 & 9.4 & \\
\hline Disabled & 17 & 24.3 & 17 & 53.1 & \\
\hline Annual household income & & & & & 0.19 \\
\hline No response & 6 & 8.5 & 1 & 3.1 & \\
\hline$<\$ 15,000$ & 44 & 62.9 & 28 & 87.5 & \\
\hline$\$ 15,001-\$ 30,000$ & 13 & 18.6 & 1 & 3.1 & \\
\hline$\$ 30,000-\$ 60,000$ & 6 & 8.6 & 2 & 6.2 & \\
\hline$\$ 100,000+$ & 1 & 1.4 & 0 & 0.0 & \\
\hline $\begin{array}{l}\text { Currently enrolled in nutrition assistance } \\
\text { program/receiving WIC, EBT, food stamps }\end{array}$ & 41 & 58.6 & 20 & 62.5 & 0.71 \\
\hline Clinical characteristics & & & & & \\
\hline Currently has health insurance & 64 & 91.4 & 31 & 96.9 & 0.57 \\
\hline Health insurance, type & & & & & 0.71 \\
\hline Fee-for-service health plan & 4 & 5.7 & 0 & 0.0 & \\
\hline $\mathrm{HMO}$ & 2 & 2.9 & 0 & 0.0 & \\
\hline POS health plan & 1 & 1.4 & 0 & 0.0 & \\
\hline $\mathrm{PPO}$ & 4 & 5.7 & 2 & 6.2 & \\
\hline Medicaid & 36 & 51.4 & 19 & 59.4 & \\
\hline Medicare & 17 & 24.3 & 9 & 28.1 & \\
\hline Quality of life & & & & & 0.61 \\
\hline
\end{tabular}

Quality of life 
Table 1 (continued)

\begin{tabular}{|c|c|c|c|c|c|}
\hline & \multicolumn{2}{|c|}{ Enrolled $(n=70)$} & \multicolumn{2}{|c|}{ Non-enrolled $(n=32)$} & \multirow[t]{2}{*}{$P$ value* } \\
\hline & $n$ & $\%$ & $n$ & $\%$ & \\
\hline Excellent & 7 & 10.0 & 3 & 9.4 & \\
\hline Very good & 8 & 11.4 & 6 & 18.8 & \\
\hline Good & 30 & 42.9 & 9 & 28.1 & \\
\hline Fair & 24 & 34.3 & 13 & 40.6 & \\
\hline Poor & 1 & 1.4 & 1 & 3.1 & \\
\hline Overall quality of life, mean (SD) & \multicolumn{2}{|c|}{$6.9(1.9)$} & & $6.9(2.2)$ & 0.98 \\
\hline Cancer stage & & & & & 0.18 \\
\hline DCIS & 20 & 28.6 & 2 & 6.2 & \\
\hline I & 27 & 38.6 & 15 & 46.9 & \\
\hline II & 14 & 20.0 & 9 & 28.1 & \\
\hline $\mathrm{III} / \mathrm{LABC}$ & 8 & 11.4 & 6 & 18.8 & \\
\hline HER2 positive & 12 & 17.1 & 4 & 12.5 & 0.04 \\
\hline Radiation therapy & 44 & 62.9 & 25 & 78.1 & 0.13 \\
\hline Chemotherapy & 34 & 48.6 & 21 & 65.6 & 0.11 \\
\hline Comorbidity index, mean (SD) & 1.1 & & 1.3 & & 0.37 \\
\hline
\end{tabular}

* $P$ values $<0.05$ were considered statistically significant

Do not add up to $100 \%$ due to missing data: education, annual household income, annual household income, health insurance, health insurance type, menopausal status, cancer stage

$H S$ high school, GED general education diploma, WIC Special Supplemental Nutrition Program for Women, Infants, and Children, EBT electronic benefits transfer, $H M O$ health maintenance organization, $P O S$ point of service, $P P O$ preferred provider organization, $S D$ standard deviation, $D C I S$ ductal carcinoma in situ, $L A B C$ locally advanced breast cancer

in the predominantly Spanish-speaking Dominican neighborhood surrounding the Columbia University Medical Center. The majority of participants in the overall sample were apartment dwellers (91.2 \%) living in Manhattan (61.8\%). Over half of the sample (59.8\%) reported being currently enrolled in nutrition assistance programs such as the Special Supplemental Nutrition Program for Women, Infants, and Children (WIC) or the Supplemental Nutrition Assistance Program (SNAP).

The majority of eligible enrolled and non-enrolled women reported their race/ethnicity as white (40 vs. $34.4 \%$ ), followed by black ( 28.1 vs. $35.7 \%$ ). Enrolled participants less frequently identified as being Native American compared to non-enrolled participants (2.9 vs. $12.5 \%$ ). More enrolled participants reported being of mixed race compared to non-enrolled participants (15.7 vs. $3.1 \%$ ). Women who were employed were more likely to enroll, compared to women who were unemployed $(P=0.048)$.

\section{Clinical Characteristics}

Eligible enrolled and non-enrolled participants were similar in mean years since diagnosis (Table 1). There were no meaningful differences in quality of life between groups. Compared to enrolled participants, non-enrolled participants had laterstage cancers, though the difference was not statistically significant. Similarly, compared to women who enrolled, women who did not enroll had a trend toward receiving more radiation ( $P=0.13)$ and chemotherapy $(P=0.11)$, as would be reflective of a higher-stage disease. Having a HER2+ tumor was a significant predictor of enrollment $(P=0.04)$. On average, participants reported $1.2( \pm 1.5)$ comorbidities (data not shown). There were no meaningful differences in comorbidities between groups (Table 1).

\section{Acculturation}

Table 2 presents acculturation measures by enrollment status. In general, enrolled women reported a higher degree of acculturation, compared to non-enrolled women. Compared to women who enrolled, women who did not enroll were more likely to report Spanish as the only language read or spoken $(P=0.02)$ and usually having thoughts only in Spanish $(P=0.03)$. The mean acculturation index was equivalent for both enrolled and non-enrolled women, indicating low levels of acculturation in both groups.

Perceptions and Attitudes Toward Research and Participation

Eligible enrolled participants consistently reported more positive perceptions and attitudes toward research and participation when compared to non-enrolled participants (Table 3). Compared to enrolled participants, participants who did not enroll were more likely to believe that they would experience 
Table 2 Acculturation, by enrollment status

$\frac{\text { Enrolled }(n=70)}{n}$

What was the language(s) you used as a child?

Only Spanish

More Spanish than English

Both equally

More English than Spanish

Only English

In general, What language(s) do you read and speak?

Only Spanish

More Spanish than English

Both equally

More English than Spanish

Only English

What language(s) do you usually speak at home? ${ }^{a}$

Only Spanish

More Spanish than English

Both equally

More English than Spanish

Only English

In what languages do you usually think? ${ }^{\mathrm{a}}$

Only Spanish

More Spanish than English

Both equally

More English than Spanish

Only English

In general, what language(s) are the movies, TV and radio programs you prefer to watch and listen to? ${ }^{\mathrm{a}}$ Only Spanish

More Spanish than English

Both equally

More English than Spanish

Only English

Can you read in Spanish?

Yes

No

Can you write in Spanish?

Yes

No

Can you read in English?

Yes

No

Can you write in English?

Yes

No

Your close friends are...? ${ }^{\mathrm{a}}$

All Hispanic/Latino

More Hispanic/Latino than non-Hispanic/Latino

About half and half
Non-enrolled $(n=32)$

$P$ value*

$n \quad \%$

$\%$

0.96

90.6

3.1

3.1

3.1

0

0.02

81.2

12.5

0.0

6.2

0.0

0.62

68.8

21.9

3.1

6.2

0.0

0.03

84.4

3.1

3.1

9.4

0.0

0.81

53.1

21.9

15.6

9.4

0.0

0.50

100

0.0

100.0

0.0

31.2

68.8

$45.7 \quad 10$

$51.4 \quad 22$

25.0

75.0

0.89 
Table 2 (continued)

$\begin{array}{cccc}\frac{\operatorname{Enrolled}(n=70)}{n} & \frac{\text { Non-enrolled }(n=32)}{n} & P \text { value* }\end{array}$

You prefer going to social gatherings/parties at which people are...?

All Hispanic/Latino

More Hispanic/Latino than non-Hispanic/Latino

About half and half

The persons you visit or who visits you are...? ${ }^{\mathrm{a}}$

All Hispanic/Latino

More Hispanic/Latino than non-Hispanic/Latino

About half and half

More non-Hispanic/Latino than Hispanic/Latino

If you could choose your children's friends you would want them to be...? ${ }^{\mathrm{a}}$

\section{All Hispanic/Latino}

More Hispanic/Latino than non-Hispanic/Latino

About half and half

More non-Hispanic/Latino than Hispanic/Latino

How often do you eat food from your culture?

Everyday

4-5 times per week

2-3 times per week

Once per week

Less than once per week

How often do you cook food from your culture?

Everyday

4-5 times per week

2-3 times per week

Once per week

Less than once per week

Acculturation index

Mean, (SD)

Range

\begin{tabular}{|c|c|c|c|c|}
\hline & & & & 0.40 \\
\hline 30 & 42.9 & 18 & 56.2 & \\
\hline 13 & 18.6 & 3 & 9.4 & \\
\hline 25 & 35.7 & 11 & 34.4 & \\
\hline & & & & 0.74 \\
\hline 43 & 61.4 & 23 & 71.9 & \\
\hline 13 & 18.6 & 5 & 15.6 & \\
\hline 11 & 15.7 & 4 & 12.5 & \\
\hline 1 & 1.4 & 0 & 0.0 & \\
\hline & & & & 0.61 \\
\hline 24 & 34.3 & 9 & 28.1 & \\
\hline 6 & 8.6 & 4 & 12.5 & \\
\hline 36 & 51.4 & 19 & 59.4 & \\
\hline 1 & 1.4 & 0 & 0.0 & \\
\hline & & & & 0.88 \\
\hline 36 & 51.4 & 17 & 53.1 & \\
\hline 10 & 14.3 & 7 & 21.9 & \\
\hline 13 & 18.6 & 4 & 12.5 & \\
\hline 5 & 7.1 & 2 & 6.2 & \\
\hline 5 & 7.1 & 2 & 6.2 & \\
\hline & & & & 0.89 \\
\hline 34 & 48.6 & 14 & 43.8 & \\
\hline 13 & 18.6 & 5 & 15.6 & \\
\hline 12 & 17.1 & 7 & 21.9 & \\
\hline 5 & 7.1 & 2 & 6.2 & \\
\hline 5 & 7.1 & 4 & 12.5 & \\
\hline & & & & 0.79 \\
\hline & & 1.5 & & \\
\hline 0.4 & & 1.0 & & \\
\hline
\end{tabular}

* Statistically significant $P=<.05$

${ }^{\text {a }}$ Variable used in the construction of the acculturation index (range 1-5, where $1=$ low and $5=$ high)

unanticipated side effects (57 vs. $75 \%, P=0.08)$ and that it would cost them too much money to participate (24 vs. $45 \%$, $P=0.04$ ). Although not statistically significant, when compared to eligible enrolled participants, nearly twice as many women in the non-enrolled group believed that research participants should be monetarily compensated for participation (44 vs. $27 \%, P=0.08$ ).

\section{Reasons for Non-participation}

Bilingual study staff attempted to contact all eligible women to schedule the baseline clinic visit, and 32 of the 102 women were unable to be scheduled. Of the 32 women, only 13 were able to be contacted by phone. Of the 13 women, reasons for non-participation varied, including lack of interest in dietary change (48\%), being too sick (15\%), moving out of country $(15 \%)$, travel (15\%), and work constraints $(8 \%)$.

\section{Discussion}

We examined factors related to participation in a culturally based behavioral intervention trial among urban Spanishspeaking Hispanic breast cancer survivors. Our study results suggest that enrollment into the ¡Cocinar Para Su Salud! dietary modification trial was affected by different factors, including socioeconomic and cultural factors, and perceptions and attitudes toward research. Despite the fact that the study was designed to be inclusive of the targeted population (i.e., 
Table 3 Attitudes toward research among enrolled and non-enrolled participants assessed at screening

\begin{tabular}{|c|c|c|c|}
\hline & $\begin{array}{l}\text { Enrolled }(n=70) \\
\%\end{array}$ & $\begin{array}{l}\text { Non-enrolled }(n=32) \\
\%\end{array}$ & $P$ value* \\
\hline If you participate in research, you will get better medical care than you would get otherwise & & & 0.67 \\
\hline Strongly disagree & 21.4 & 18.8 & \\
\hline Disagree somewhat & 18.6 & 9.4 & \\
\hline Agree somewhat & 24.3 & 28.1 & \\
\hline Strongly agree & 34.3 & 43.8 & \\
\hline If you participate in research, you may experience side effects that the doctors cannot predict & & & 0.08 \\
\hline Strongly disagree & 11.4 & 15.6 & \\
\hline Disagree somewhat & 28.6 & 12.5 & \\
\hline Agree somewhat & 47.1 & 46.9 & \\
\hline Strongly agree & 8.6 & 25.0 & \\
\hline If you participate in research, you can help others & & & 0.88 \\
\hline Strongly disagree & 1.4 & 0.0 & \\
\hline Disagree somewhat & 4.3 & 6.2 & \\
\hline Agree somewhat & 14.3 & 12.5 & \\
\hline Strongly agree & 80.0 & 81.2 & \\
\hline If you participate in research, your personal information will be kept confidential & & & 0.07 \\
\hline Strongly disagree & 1.4 & 3.1 & \\
\hline Disagree somewhat & 0.0 & 6.2 & \\
\hline Agree somewhat & 22.9 & 34.4 & \\
\hline Strongly agree & 75.7 & 56.2 & \\
\hline If you participate in research, it will cost you too much money & & & 0.03 \\
\hline Strongly disagree & 64.3 & 40.6 & \\
\hline Disagree somewhat & 24.3 & 25.0 & \\
\hline Agree somewhat & 10 & 31.2 & \\
\hline Strongly agree & 1.4 & 0.0 & \\
\hline If you participate in research, it will take too much time & & & 0.28 \\
\hline Strongly disagree & 25.7 & 12.5 & \\
\hline Disagree somewhat & 25.7 & 25.0 & \\
\hline Agree somewhat & 42.9 & 53.1 & \\
\hline Strongly agree & 2.9 & 9.4 & \\
\hline Doctors who do research care more about the research than about the patients & & & 0.93 \\
\hline Strongly disagree & 31.4 & 31.2 & \\
\hline Disagree somewhat & 32.9 & 37.5 & \\
\hline Agree somewhat & 28.6 & 25.0 & \\
\hline Strongly agree & 5.7 & 3.1 & \\
\hline If you participate in research, you should get paid for it & & & 0.23 \\
\hline Strongly disagree & 41.4 & 25.0 & \\
\hline Disagree somewhat & 32.9 & 34.4 & \\
\hline Agree somewhat & 18.6 & 28.1 & \\
\hline Strongly agree & 4.3 & 12.5 & \\
\hline If you participate in research, you have to fill out a lot of confusing forms & & & 0.51 \\
\hline Strongly disagree & 11.4 & 6.2 & \\
\hline Disagree somewhat & 15.7 & 12.5 & \\
\hline Agree somewhat & 44.3 & 62.5 & \\
\hline Strongly agree & 27.1 & 18.8 & \\
\hline
\end{tabular}

staff were representative of the patient population, all study activities were conducted in Spanish, and the intervention itself was culturally based), key factors were identified as being associated with lower rates of participation, including 
unemployment, being monolingual (Spanish speaking), and perceiving that research is costly to participants. There were a number of important factors related to socioeconomic status, clinical characteristics, acculturation, and perceptions toward research that were not associated with trial enrollment, and these can be considered as hypothesis generating for future studies. Given that Hispanic breast cancer survivors have a poorer prognosis when compared to non-Hispanic white women, even when adjusting for stage at diagnosis [34], it is important to include this population of women in clinical trials testing strategies to improve prognosis, including behavioral interventions.

It is well documented that compared to other populations, Hispanics are less likely to enroll and participate in clinical trials [17, 35-38]. However, studies focused specifically on Hispanic breast cancer survivors are needed to better understand the specific reasons for non-enrollment of eligible individuals in this population. To our knowledge, no other studies have focused on eligible non-enrolled Hispanic breast cancer survivors. In a recent review of randomized controlled trials among women with breast cancer, only half of the trials reported trial recruitment processes [39]. The majority of the currently published literature focuses on barriers of initial enrollment of non-consented individuals with unknown eligibility status. A recent review of 65 studies examining initial enrollment barriers into cancer trials has focused on AfricanAmerican populations [18]. These studies identified low education, high monetary costs, perceived harm, mistrust, and cultural factors such as language as barriers to participation [7, 18, 23, 40-43]. Although there are parallels with barriers identified in these studies and our current study (i.e., financial burden), exploring non-enrollment among eligible individuals may yield a more comprehensive understanding of reasons for non-participation. Such information is vital to the recruitment of representative samples, and it informs our ability to maintain adherence to participation at baseline and throughout the study duration.

Difficulties in the recruitment of diverse populations into trials are rooted in many sociodemographic factors including race/ethnicity, language, income, socioeconomic status, and education [44-46]. A systematic review of cancer-related trials examining barriers to recruitment of underrepresented populations, including African-Americans, Hispanics, Asian Americans, Pacific Islanders, and American Indians/Alaska Natives, reports that low socioeconomic status is a consistent barrier [18]. A recent cross-sectional study examining participation in clinical trials among more than 5000 women reported lower odds of participation among individuals with lower income levels and a potential negative association between participation and age, gender, education, and comorbidities, although this sample was predominantly non-Hispanic white [43]. These studies were consistent with our findings that suggested a decreased likelihood of participation due to financial burdens related to true and perceived costs. Results from a recent qualitative assessment of investigator experiences and perspectives on barriers to minority recruitment also support these findings [9]. Multilevel barriers including low socioeconomic status and education, distrust, and competing personal obligations were documented in several studies conducted within National Cancer Institute (NCI)-designated cancer centers across the US [9]. Similar results have been reported in studies investigating the influence of race, income, and language on participation among eligible non-enrolled individuals. Low rates of enrollment have been observed in analyses of over 50 therapeutic clinical trials, stratified by race and four cancer types including lung, colorectal, prostate, and breast [17]. Higher rates of non-participation among eligible enrolled individuals have been reported among Hispanics when compared to other ethnic groups [47]. Low levels of participation among racial/ethnic minorities including Hispanics appear to transcend differences in socioeconomic status, including being given the adequate opportunity to participate in studies and being provided with an adequate opportunity to decide whether to accept or refuse participation $[9,18]$. Shared "word of mouth" communications among friends and/or family members about study enrollment opportunities have been shown to improve participation, suggesting that this strategy may help overcome some of the previously addressed barriers to participation [47-49]. Additional strategies such as having adequate staffing, strong study staff rapport with participants, and short interviews with minimal time commitment have been identified as influencing recruitment and retention among low-income minority participants [50]. Coaching intervention studies have reported conflicting results regarding its effectiveness on improving patient willingness to participate in clinical trials $[48,51,52]$.

There is a body of literature suggesting that mistrust of scientific investigators and risks and benefits related to participation play a significant role in non-enrollment rates [53-55]. Though our sample size was relatively small, we did not observe similar findings, which may be due to chance, or may be a true finding among this specific patient population. Several studies have evaluated the effect of randomization on the decision to participate in trials [53, 56-59]. Two studies among African-Americans found negative perceptions and attitudes toward the randomization process based upon beliefs that unwanted or ineffective interventions would be provided $[53,56]$. In contrast, the majority of women in our study agreed with the notion that participation in research would yield better medical care than they would otherwise receive, and there was no differential mistrust between enrolled and non-enrolled women.

Similarly, health insurance status was not associated with trial participation. Our population had high rates $(>75 \%)$ of government-based health insurance. In general, private and government insurance coverage is less likely among Caribbean-born immigrants when compared to foreign-born immigrants [60], but our population of patients recruited from 
a clinical setting was highly insured. It is possible that enrollment in private and government insurance coverage is not equally distributed among the various ethnic groups and perhaps explains some of the varying barriers and facilitators across groups.

Interestingly, we observed a trend of higher rates of participation among women with better clinical prognosis based upon tumor stage and histology. Previous studies have suggested that patients with a more advanced disease have more positive attitudes toward clinical trials [61]. However, the majority of that research is in therapeutic trials and not in behavioral interventions.

Strengths of our study included the ability to collect and assess factors related to non-participation in a randomized behavioral intervention study conducted among a diverse population of urban Spanish-speaking Hispanic breast cancer survivors. Additionally, the use of previously validated acculturation and comorbidity measures strengthens the reliability of our reported results. A limitation of our study was that screening questionnaire data was self-reported and all screened participants were eligible, thereby introducing the potential for selection bias. Additionally, there was a low response rate for reasons of non-participation. These results should be interpreted cautiously as there is a potential bias due to loss to follow-up. We did not have data regarding whether word of mouth influenced enrollment or could influence enrollment in future studies.

In summary, our study describes the role of specific socioeconomic factors, acculturation, and perceptions of research on participation in a behavioral intervention trial among Spanish-speaking Hispanic breast cancer survivors. This patient population is increasing in the US and it is important that they are adequately represented in clinical trials. Our findings demonstrate that even in a culturally based behavioral intervention trial, there are persistent underlying factors associated with disparate participation rates among Hispanic breast cancer survivors. The widespread presence of coinciding barriers to participation across different regions of the US highlights the need for multilevel facilitators to increase trial participation [9]. Future trials and interventions should consider these findings at the beginning of the study design phase, as well as throughout the recruitment and retention periods. Increased participation of a diverse population of participants may be possible by developing a study design that addresses and is sensitive to socioeconomic, educational, cultural, and attitude constraints by way of a tailored, population-specific, recruitment and retention strategy.

Informed Consent All procedures followed were in accordance with the ethical standards of the responsible committee on human experimentation (institutional and national) and with the Helsinki Declaration of 1975, as revised in 2000 (5). Informed consent was obtained from all individuals who participated in this study.
Animal Studies No animal studies were carried out by the authors for this article.

Conflict of Interest Blanca Bernard-Davila, MPH, MS; A. Corina Aycinena, MS, RD; John Richardson, MA; Ann Ogden Gaffney, Pam Koch, EdD, RD; Isobel Contento, PhD; Christine Sardo Molmenti, PhD, RD; Maria Alvarez; Dawn Hershman, MD, MS; and Heather Greenlee, $\mathrm{ND}, \mathrm{PhD}$, declare that they have no conflict of interest.

Sources of Support Funding for the study was obtained from National Cancer Institute grant numbers NCI 5T32CA009529 and NCI R21 CA155973.

\section{References}

1. U.S. Census Bureau, 2011 Population Estimates: National Characteristics, U.S Department of Commerce, Edited 2012, U.S. Census Bureau.

2. Hastert TA, Beresford SA, Patterson RE, Kristal AR, White E. Adherence to WCRF/AICR cancer prevention recommendations and risk of post-menopausal breast cancer. Cancer Epidemiol Biomarkers Prev. 2013. doi:10.1158/1055-9965.epi-13-0210.

3. Chlebowski RT et al. Dietary fat reduction and breast cancer outcome: interim efficacy results from the Women's Intervention Nutrition Study. J Natl Cancer Inst. 2006;98(24):1767-76.

4. Song JK, Bae JM. Citrus fruit intake and breast cancer risk: a quantitative systematic review. J Breast Cancer. 2013;16:72-6. doi: 10.4048/jbc.2013.16.1.72.

5. Couto E et al. Mediterranean dietary pattern and cancer risk in the EPIC cohort. Br J Cancer. 2011;104:1493-9. doi:10.1038/bjc.2011.106.

6. Blackburn GL, Copeland T, Khaodhiar L, Buckley RB. Diet and breast cancer. J Womens Health (Larchmt). 2003;12:183-92.

7. Shavers VL, Burmeister LCF. Racial differences in factors that influence the willingness to participate in medical research studies. Ann Epidemiol, 2002; 12.

8. Sears SR, Stanton AL, Kwan L, Krupnick JL, Rowland JH, Meyerowitz BE, Ganz PA. Recruitment and retention challenges in breast cancer survivorship research: results from a multisite, randomized intervention trial in women with early stage breast cancer. Cancer Epidemiol Biomarkers Prev. 2003;12:1087-90.

9. Durant RW, Wenzel JA, Scarinci IC, Paterniti DA, Fouad MN, Hurd TC, Martin MY. Perspectives on barriers and facilitators to minority recruitment for clinical trials among cancer center leaders, investigators, research staff, and referring clinicians: enhancing minority participation in clinical trials (EMPaCT). Cancer. 2014;120:1097-105. doi:10.1002/cncr.28574.

10. Howlader N, Noone AM, Krapcho M, Garshell J, Miller D, Altekruse SF, Kosary CL, Yu M, Ruhl J, Tatalovich Z, Mariotto A, Lewis DR, Chen HS, Feuer EJ, Cronin KA (eds). SEER Cancer Statistics Review, 1975-2009 (Vintage 2009 Populations), N.C. Institute, Editor 2012, National Cancer Institute: Bethesda, MD.

11. Suro R, Singer A. Latino growth in metropolitan America: changing patterns, new locations. Washington DC: The Brookings Institution; 2002.

12. Motel S, Patten E. Characteristics of the 60 largest metropolitan areas by Hispanic population. Washington DC: Pew Hispanic Center; 2012.

13. Lopez M, Gonzalez-Barrera A. What is the future of Spanish in the United States? Washington DC: Pew Research Center; 2013.

14. Des Jarlais G, Kaplan CP, Haas JS, Gregorich SE, Pérez-Stable EJ, Kerlikowske K. Factors affecting participation in a breast cancer risk reduction telephone survey among women from four racial/ethnic groups. Prev Med. 2005;41(3-4):720-7.

15. Yancey AK, Ortega AN, Kumanyika SK. Effective recruitment and retention of minority research participants. Annu Rev Public Health. 2006;27:1-28. 
16. Profile America, Facts for Features, 2011, United States Department of Commerce: Census Bureau.

17. Murthy V, Krumholz HM, Gross CP. Participation in cancer clinical trials: race-, sex- and age-based disparities. JAMA. 2004;291: 2720-6.

18. Ford JG, Howeton MW, Lai GY, Gary TL, Boien S, Gibbons MC, et al. Barriers to recruiting underrepresented populations to cancer clinical trials: a systematic review. Cancer. 2008;112:228-42.

19. Bates BR, Lynch JA, Bevan JL, Condit CM. Warranted outlooks: a focus group study of public understandings of genetic research. Soc Sci Med. 2005;60:331-44.

20. Schulz A, Caldwell C, Foster S. What are they going to do with the information? Latino/Latina and African American perspectives on the Human Genome Project. Health Educ Behav. 2003;30:151-69.

21. Sterling R, Henderson GE, Corbie-Smith G. Public willingness to participate in and public opinions about genetic variation research: a review of the literature. Am J Public Health. 2006;96(11):1971-8.

22. Shavers VL, Lynch CF, Burmeister LF. Factors that influence African-Americans' willingness to participate in medical research studies. Cancer. 2001;91:233-6.

23. Harris Y, Gorelink PB, Samuels P, Bempong I. Why African Americans may not be participating in clinical trials. J Natl Cancer Inst. 1996;88:630-4.

24. Robinson S, Ashley M, Haynes MA. Attitude of African Americans regarding prostate cancer clinical trials. J Commun Health. 1996;21:77-8.

25. Greenlee H, G.A., Aycinena AC, Koch P, Contento I, Karmally W, Richardson J, Tsai WY, Crew K, Maurer M, Kalinsky K, Hershman D Cocinar Para Su Salud!: Effects of a culturally-tailored dietary intervention on fruit/vegetable and fat intake among Hispanic breast cancer survivors. American Society of Preventive Oncology, 2013.

26. Greenlee H, Aycinena AC, Richardson J, Gaffney OA, Koch P, Contento I, Hershman D, Cocinar Para Su Salud!: Randomized controlled trial of a culturally-based dietary intervention among Hispanic breast cancer survivors (in submission to the Journal of Nutrition and Dietetics). 2014

27. Bernard-Davila B, Aycinena AC, Richardson J, Gaffney AO, Koch P, Contento I, Hershman D, Greenlee H. Barriers and facilitators to recruitment in a dietary intervention among urban Hispanic breast cancer survivors [abstract], in Proceedings of the Twelfth Annual AACR International Conference on Frontiers in Cancer Prevention Research 2013 Oct 27-30.

28. Daviglus ML et al. Prevalence of major cardiovascular risk factors and cardiovascular diseases among Hispanic/Latino individuals of diverse backgrounds in the United States. JAMA. 2012;308:177584. doi:10.1001/jama.2012.14517.

29. Marín G, Sabogal F, VanOss Marín B, Otero-Sabogal F, Pérez-Stable EJ. Development of a short acculturation scale for Hispanics. Hisp J Behav Sci. 1987;9:183-205.

30. Charlson M, Pompei P, Ales KL, MacKenzi CR. A new method of classifying prognostic comorbidity in longitudinal studies: development and validation. J Chronic Dis. 1987;40:373-83.

31. Patterson R, Flatt SW, Saquib N, Rock CL, et al. Medical comorbidities predict mortality in women with a history of early stage breast cancer. Breast Cancer Res Treat. 2010;859-865.

32. Kibler JL, Brisco K. Evaluation of a brief questionnaire for assessing barriers to research participation. Ethn Dis. 2006;16(2):547-50.

33. Barakat LP, Patterson CA, Mondestin V, Chavez V, Austin T, Robinson MR, Li Y, Smith-Whitley K, Cohen R. Initial development of a questionnaire evaluating perceived benefits and barriers to pediatric clinical trials participation. Contemp Clin Trials. 2013;34(2):218-26.

34. American Cancer Society. Cancer facts \& figures for Hispanics/ Latinos. Atlanta: American Cancer Society; 2012.

35. Harter P, du Bois A, Schade-Brittinger C, Burges A, Wollschlaeger $\mathrm{K}$, Gropp $\mathrm{M}$, et al. Non-enrolment of ovarian cancer patients in clinical trials: reasons and background. Ann Oncol. 2005;16:1801-5.
36. Green BB, Bogart A, Chubak J, Vernon SW, Morales LS, Meenan RT, et al. Nonparticipation in a population-based trial to increase colorectal cancer screening. Am J Prev Med. 2012;43:390-7.

37. Symonds RP, Lord K, Mitchell AJ, Raghavan D. Recruitment of ethnic minorities into cancer clinical trials: experience from the front lines. Br J Cancer. 2012;107:1017-21.

38. Wendler D, Kington R, Madans J, Van Wye G, Christ-Schmidt H, Pratt LA, et al. Are racial and ethnic minorities less willing to participate in health research? PLoS Med. 2006;3(3):e19.

39. Gross CP, Mallory R, Heiat A, Krumholz HM. Reporting the recruitment process in clinical trials: who are these patients and how did they get there? Ann Intern Med. 2002;137:10-6.

40. Lang R, Kelker VA, Byrd JR, Edwards CL, Pericak-Vance M, Byrd GS. African American participation in health-related research studies: indicators for effective recruitment. J Public Health Manag Pract. 2013;19:110-8.

41. Advani AS, Atkeson B, Brown CL, Peterson BL, Fish L, Johnson JL, Gockerman JP, Gautier M. Barriers to the participation of AfricanAmerican patients with cancer in clinical trials: a pilot study. Cancer. 2003;97:1499-506. doi:10.1002/cncr.11213.

42. Chamberlain RM, Winter KA, Vijayakumar S, Porter AT, Roach M 3rd, Streeter O, Cox JD, Bondy ML. Sociodemographic analysis of patients in radiation therapy oncology group clinical trials. Int $\mathrm{J}$ Radiat Oncol Biol Phys. 1998;40:9-15.

43. Unger JM HD, Albain KS, Moinpour CM, Petersen JA, Burg K, Crowley JJ. Patient income level and cancer clinical trial participation. J Clin Oncol. 2013;31(5):536-42.

44. Brown DR, Fouad MN, Basen-Engquist K, Tortolero-Luna G. Recruitment and retention of minority women in cancer screening, prevention, and treatment trials. Ann Epidemiol. 2000;10(8 suppl):S13-21.

45. Brown DR, Topcu M. Willingness to participate in clinical treatment research among older African Americans and whites. Gerontologist. 2003;43:62-72.

46. Sateren WB, Trimble E, Abrams J, Brawley O, Breen N, Ford L, et al. How sociodemographics, presence of oncology specialists, and hospital cancer programs affect accrual to cancer treatment trials. J Clin Oncol. 2002;20:109-1017.

47. Coronado GD, Ondelacy S, Schwarz Y, Duggan C, Lampe JW, Neuhouser ML. Recruiting underrepresented groups into the carbohydrates and related biomarkers (CARB) cancer prevention feeding study. Contemp Clin Trials. 2012;33:641-6. doi:10.1016/j.cct.2012.03.017.

48. Fracasso PM, Goodner SA, Creekmore AN, Morgan HP, Foster DM, Hardmon AA, Engel SJ, Springer BC, Mathews KJ, Fisher EB, Walker MS. Coaching intervention as a strategy for minority recruitment to cancer clinical trials. J Oncol Pract. 2013;9:294-9. doi:10. 1200/jop.2013.000982.

49. Brown SD, Lee K, Schoffman DE, King AC, Crawley LM, Kiernan M. Minority recruitment into clinical trials: experimental findings and practical implications. Contemp Clin Trials. 2012;33:620-3. doi:10. 1016/j.cct.2012.03.003.

50. Barnett J, Aguilar S, Brittner M, Bonuck K. Recruiting and retaining low-income, multi-ethnic women into randomized controlled trials: successful strategies and staffing. Contemp Clin Trials. 2012;33(5):925-32.

51. Fisher EB, Strunk RC, Sussman LK, Sykes RK, Walker MS. Community organization to reduce the need for acute care for asthma among African American children in low-income neighborhoods: the Neighborhood Asthma Coalition. Pediatrics. 2004;114:116-23.

52. Kalauokalani D, Franks P, Oliver JW, Meyers FJ, Kravitz RL. Can patient coaching reduce racial/ethnic disparities in cancer pain control? Secondary analysis of a randomized controlled trial. Pain Med. 2007;8:17-24. doi:10.1111/j.1526-4637.2007.00170.x.

53. Corbie-Smith G, Thomas SB, Williams MV, Moody-Ayers S. Attitudes and beliefs of African Americans toward participation in medical research. J Gen Intern Med. 1999;14:537-46.

54. Swanson GM, Ward AJ. Recruiting minorities into clinical trials: toward a participant-friendly system. J Natl Cancer Inst. 1995;87:1747-59. 
55. Ford ME, Siminoff LA, Pickelsimer E, Mainous AG, Smith DW, Diaz VA, et al. Unequal burden of disease, unequal participation in clinical trials: solutions from African American and Latino community members. Health Soc Work. 2013;38:29-38.

56. Lacher M. Patients and physicians as obstacles to a randomized trial. Semin Oncol. 1981;8:424-9.

57. Millon-Underwood S, Sanders E, Davis M. Determinants of participation in state-of-the-art cancer prevention, early detection/screening, and treatment trials among African-Americans. Cancer Nurs. 1993;16:25-33.

58. Ford LG, Minasian LM, McCaskill-Stevens W, Pisano ED, Sullivan D, Smith RA. Prevention and early detection clinical trials: opportu- nities for primary care providers and their patients. CA Cancer J Clin. 2003;53:82-101.

59. Wright JR, Whelan TJ, Schiff C, Dubois S, Crooks D, Haines PT, et al. Why cancer patients enter randomized clinical trials: exploring the factors that influence their decision. J Clin Oncol. 2004;22:4312-8.

60. Carrasquillo O, Carrasquillo A, Shea S. Health insurance coverage of immigrants living in the United States: differences by citizenship status and country of origin. Am J Public Health. 2000;90:917-23.

61. Melisko ME, Hassin F, Metzroth L, Moore DH, Brown B, Patel K, Rugo HS, Tripathy D. Patient and physician attitudes toward breast cancer clinical trials: developing interventions based on understanding barriers. Clin Breast Cancer. 2005;6:45-54. doi:10.3816/CBC. 2005.n.008. 